\title{
Fecundity of transgenic wild-crop hybrids of Cucurbita pepo (Cucurbitaceae): implications for crop-to-wild gene flow
}

\author{
LAWRENCE J. SPENCER* \& ALLISON A. SNOW \\ Department of Evolution, Ecology, and Organismal Biology, Ohio State University, 1735 Neil Avenue, \\ Columbus, $\mathrm{OH}$ 43210-1293, U.S.A.
}

\begin{abstract}
Hybridization between crops and their weedy or wild relatives is an area of concern because the widespread use of genetically engineered crops may allow novel, beneficial transgenes to enter nearby populations. We compared fitness components of wild Cucurbita pepo from Arkansas, USA, with wild-crop hybrids derived from yellow squash (a cultivar of $C$. pepo with transgenic resistance to two viruses). Wild and hybrid progeny were grown in agricultural fields in Arkansas (1996-98) and Ohio (1996) in six similar experiments. Cross types (wild and hybrid) did not differ significantly in seedling survival, which exceeded $85 \%$ in all cases. In Ohio, where more detailed observations were made, hybrid plants produced $41 \%$ as many male flowers, $21 \%$ as many female flowers, and $28 \%$ as many seeds as wild plants. At all sites, flowering periods of the two cross types overlapped extensively. Putative virus symptoms were more common in wild plants than in hybrids. Lifetime fecundity varied considerably among sites and years. The average fecundity of hybrids ranged from 453 to 4497 seeds per plant and represented $15 \%-53 \%$ of the numbers of seeds produced by wild plants in the same experiments. These results suggest that the $F_{1}$ generation does not represent a strong barrier to the introgression of neutral or beneficial crop genes into free-living populations of C. pepo.
\end{abstract}

Keywords: Cucurbita pepo, fecundity, gene flow, squash, transgenic, wild-crop hybridization.

\section{Introduction}

Small (1984) hypothesized that weeds owe much of their evolutionary success to hybridization with other varieties and species, including domesticated relatives. Crops such as rice, sunflower, oilseed rape, squash, sorghum, sugar beet, and carrot are known to hybridize with wild and/or weedy relatives (e.g. Snow \& Morán Palma, 1997; Ellstrand et al., 1999). However, the potential benefits of crop genes to populations of wild relatives are not known. Many domestic traits do not afford any known benefit to wild plants and some, such as lack of seed shattering, may be detrimental (e.g. Small, 1984; Van Gaal et al., 1998). Evidence for benefits of crop-towild gene flow is becoming more clear, but is often sketchy since it is only recently that many studies have concentrated on this process (see Snow et al., 1998; Ellstrand et al., 1999).

A great deal of interest in wild-crop hybridization has been generated by the development of genetically engineered cultivars with resistance traits that may benefit wild

*Correspondence. E-mail: spencer.120@osu.edu or weedy relatives. For example, Jørgensen \& Andersen (1994) showed that Brassica napus (oilseed rape, $2 n=38$ ) and $B$. campestris (a weedy relative, $2 n=20$ ) spontaneously hybridize in the field, even though artificial crosses between the two species were often unsuccessful. In another crop-weed system, Arriola \& Ellstrand (1996, 1997) demonstrated that gene flow can occur naturally between the annual crop Sorghum bicolor and johnson grass ( $S$. halepense), a widespread perennial weed. Interspecific hybrids did not differ from johnson grass in several fitness parameters, suggesting that there is no apparent barrier to prevent neutral or beneficial crop genes from moving into populations of the weed. In some cases, $F_{1}$ progeny may be even more vigorous than their wild parents, as reported in rice (Langevin et al., 1990) and radish (Klinger \& Ellstrand, 1994). Although these studies suggest that hybridization between wild and crop relatives is very likely, other crop-weed complexes exhibit stronger barriers to gene flow and introgression (e.g. Renno et al., 1997; Zemetra et al., 1998; Jiang et al., 2000).

In native North American species such as squash and sunflower, studies involving selectively neutral genetic 
markers have shown that long-term and continuing genetic exchange occurs between crops and their wild and weedy relatives (Decker, 1988; Wilson, 1990; Linder et al., 1998). This illustrates that gene flow, hybridization, and introgression have occurred in the past, but we know relatively little about the rate at which hybridization is occurring in existing crop/wild complexes. Hybridization should occur most rapidly when pollinators move frequently between the crop and the wild relative, resulting in fertile $F_{1}$ hybrids. Moreover, variability of offspring obtained from hybridization may be quite high, allowing a few variant genotypes to achieve high fitness even if most hybrids have much lower fitness (Arnold, 1997; Rieseberg \& Linder, 1999). The fecundity of hybrids relative to wild plants is also likely to vary geographically and temporally due to genotypeby-environment interactions (e.g. Snow et al., 1998).

In Cucurbita pepo, Kirkpatrick \& Wilson (1988) found that crop-to-wild hybridization was common. Pollinating bees transferred pollen over distances exceeding $1000 \mathrm{~m}$. Long-distance pollen dispersal suggests that the eventual spread of transgenes, at least to an $F_{1}$ generation, is likely in areas of the south-central USA where the crop occurs near free-living populations (Kirkpatrick \& Wilson, 1988; Wilson, 1993). In 1994, the US Department of Agriculture (USDA) deregulated a transgenic, virus-resistant cultivar of $C$. pepo after concluding that the transgene was unlikely to persist in free-living squash populations (USDA/APHIS, 1994). Crop breeders and government regulators sometimes assume that crop genes will be disadvantageous to wild populations and will not be able to spread. However, it is important to quantify fitness components of $F_{1}$ cropwild hybrids and backcrossed generations to determine whether there are any barriers to subsequent introgression. Obtaining this information for wild squash is especially important because such studies have not been reported in peer-reviewed publications, and transgenic varieties have already been approved for commercialization. The goals of this research were to compare fitness components of $F_{1}$ wild-crop hybrids with those of wild plants within their native range (Arkansas 199698) and in central Ohio (1996). We report comparisons of seedling survival, flowering times, and lifetime fecundity, as well as data on the occurrence of putative viral symptoms.

\section{Materials and methods}

\section{Study organisms}

Cucurbita pepo is a widespread monoecious species with both free-living and cultivated varieties. Cultivars include crookneck and zucchini squashes, as well as several pumpkin and ornamental gourd varieties. The cultivar used in this research was Asgrow's Freedom II, a yellow crookneck squash (C. pepo ssp. ovifera, var. ovifera). This cultivar is resistant to two potyviruses, Zucchini Yellow Mosaic Virus (ZYMV) and Watermelon Mosaic Virus 2 (WMV2), which frequently infect cucurbit crops (Tricoli et al., 1995; Schultheis \& Walters, 1998). Another cultivar, Freedom III, is also resistant to Cucumber Mosaic Virus and was deregulated in 1995. We were not able to obtain seeds of Freedom III because it had not become available commercially and Asgrow (now Seminis Seeds) denied our requests for seeds.

Potyviruses are widespread viruses that infect many plant families and are transmitted mainly by aphids. In cucurbits, these viruses cause symptoms such as mottling, discoloration and/or malformation of leaves, flowers and fruits; chlorosis; reduced yield; and in some cases, premature death (Walkey, 1991). Freedom II has two tightly linked (tandem) viral coat protein genes in a transgene construct that confers resistance to ZYMV and WMV2 and lacks a selectable marker. These transgenes are hemizygous in the crop parents and act as dominant genes (Tricoli et al., 1995).

Unfortunately, Freedom II has three inserted copies of the transgene construct rather than one, and two of these copies appear to be located on the same chromosome (Tricoli et al., 1995). The linked copies confer strong resistance to the viruses, whereas the third copy confers weaker resistance (Tricoli et al., 1995). These constructs are detectable using a PCR screening protocol, but it is not possible to tell which copy is present without Southern blot analysis. Therefore, due to limited resources, we did not attempt to identify which $F_{1}$ progeny inherited one, two, or all three copies of the transgene construct. The data reported here focus on general attributes of wild and $F_{1}$ hybrids and do not include comparisons between transgenic and nontransgenic $F_{1}$ plants.

In the USA, free-living populations of Cucurbita pepo (ssp. ovifera, var. ozarkana and var. texana [common name $=$ Texas gourd]) occur as annuals in both cultivated and non-cultivated habitats (Wilson, 1993). These populations may represent progenitors of cultivated varieties, feral populations that escaped from cultivation, or, more likely various combinations of the two (Decker, 1988; Cowan \& Smith, 1993). Free-living C. pepo sometimes occurs as a weed in cotton and soybean fields, where the vines interfere with the growth of crop plants and the hard gourds can foul farm machinery (Weidemann \& Templeton, 1988). Wild and weedy populations are not phenotypically distinct, and genetic analyses reveal little or no differentiation between these types of populations (Decker, 1988; Cahoon, 1995). For consistency, we refer to free-living 
populations from nonagricultural areas as 'wild', although these plants are probably indistinguishable from "weedy" populations. Both types are included in the term FLCP (free-living C. pepo, as in Wilson, 1993).

FLCP is a climbing or trailing vine that grows vigorously in open, fertile sites such as riverbanks, sand bars, and cultivated fields (Wilson, 1993). The fruits (gourds) are extremely bitter due to the presence of cucurbitacins, which are common throughout the genus Cucurbita (Tallamy \& Krischik, 1989). The buoyant fruits are carried by water, which disperses the seeds to floodplains of the south-central USA, including areas in Texas, Louisiana, Arkansas, Mississippi, Alabama, Missouri, and southern Illinois (Wilson, 1993). Seeds are also dispersed by humans and farm vehicles, and densities of more than 100 plants $\mathrm{m}^{-2}$ have been documented in some agricultural areas (Cowan \& Smith, 1993).

FLCP populations are highly susceptible to common cucurbit viruses, including ZYMV, WMV2, and CMV (Provvidenti et al., 1978; Fuchs \& Gonsalves, 1999; H. Quemada, personal communication to LJS). It is widely assumed that all FLCP populations are susceptible to these viruses because wild germplasm has been screened extensively as a possible source of resistance genes for the crop. Failure to detect naturally occurring resistance in free-living C. pepo prompted biotechnology companies to use recombinant DNA techniques involving the insertion of viral coat proteins.

The wild plants used in this study were grown from seeds obtained by Dr Bruce Smith (Smithsonian Institution) from four populations in a nonagricultural region of the Buffalo-White River drainage in Independence, Izard, Searcy, and Woodruff Counties, Arkansas (see Cowan \& Smith, 1993, for site details; seeds from different populations were mixed). Fruit samples from these collections are deposited in the Archaeobiology Laboratory at the National Museum of Natural History, USA (Table 1). Because these collections come from nonagricultural habitats, it is possible that they possess fewer crop genes from past introgression than populations that occur in farmers' fields.

\section{Pollinations}

To obtain $F_{1}$ hybrids, we germinated seeds from 19 wild parents (about four per parent) and used 60 of these plants as pollen recipients. To simplify crosses, wild plants were used as the maternal parents in all crosses because we judged that the most likely direction of gene flow would be from the crop to wild relatives. This decision was based on the fact that when free-living plants cross with crops, most crop fruits and their seeds are likely to be removed during harvest. To ensure that
Table 1 Collection sites and National Museum of Natural History curatorial numbers for seeds used in this study. Collections were made between 1990 and 1995 by C. W. Cowan and B. D. Smith

\begin{tabular}{lcc}
\hline $\begin{array}{l}\text { Arkansas } \\
\text { county }\end{array}$ & $\begin{array}{c}\text { River } \\
\text { system }\end{array}$ & \multicolumn{1}{c}{ Curatorial numbers } \\
\hline Searcy & Buffalo & AB 166, AB 183, AB 200, AB 204, \\
& & AB 217, AB 225, AB 234, \\
& AB 239, AB 240, AB 262 \\
Izard & White & AB 288, AB 289, AB 294, AB 318, \\
& & AB 321, AB 331 \\
Independence & White & AB 361, AB 372 \\
Woodruff & White & AB 382 \\
\hline
\end{tabular}

there was an ample supply of crop pollen, about 60 crop plants were used as pollen donors for wild-crop crosses. Approximately 40 wild plants were used as pollen donors for wild-wild crosses to obtain genetically diverse seeds on the 60 maternal wild plants. Although the same set of wild plants was used as pollen donors and recipients, none of the crosses involved self-pollination between flowers on the same plant.

Pollinations were carried out by brushing clean cotton-tipped swabs on the anthers of male flowers and dabbing pollen onto the stigmas of recipient plants. One male flower was used for each female recipient. We did not bag female flowers before or after pollinating them, but we used extra female flowers as unpollinated 'controls' $(N>100)$. None of these flowers set fruit, nor did we see any insect pollinators inside the greenhouse, indicating that no inadvertent pollen contamination occurred. Seeds from 99 fruits were harvested from the maternal plants for use in field experiments. Approximately equal numbers of wild and hybrid fruits were taken from each maternal plant. Seeds from these crosses were used in each year of the study (1996, 1997 and 1998).

\section{6 field experiments}

In 1996, we carried out field experiments in Arkansas and Ohio. We compared the survival and lifetime fecundity of seedlings that were started in a greenhouse and transplanted to field sites when each plant had 2-3 true leaves. Due to a lack of sufficient $F_{1}$ seeds, we were not able to study seed survivorship, seed dormancy, or seedling emergence, so these components of the plants' life cycle were necessarily omitted.

One experimental field was located at the University of Arkansas Southwest Research and Extension Center, Hope, Arkansas, near the sources of wild genotypes, while the other was at the Ohio State University 
Agricultural Fields, where plants could be observed more frequently. Both fields had a sandy loam soil. The Arkansas field, designated Field 1, was fallow for three years prior to this experiment, while the Ohio field had been planted with oilseed rape in 1995. To overcome possible seed dormancy, we placed $\mathrm{F}_{1}$ and wild seeds in a drying oven overnight at $60{ }^{\circ} \mathrm{C}$ prior to germination. Seeds were planted in flats in the greenhouse. Rates of germination were more than $95 \%$ for both cross types and seedlings emerged synchronously within a period of 3-4 days. When seedlings had 2-3 true leaves, we transplanted them to the field sites, using the same planting design in both locations. The seedlings were planted in rows with one wild plant followed by two hybrid plants, allowing $5 \mathrm{~m}$ between plants and $5 \mathrm{~m}$ between rows to minimize competition between neighbouring plants. This two-to-one ratio was used because hybrid plants were expected to be more variable than wild plants. Differences between cross types were large at both sites, as well as in later experiments, so we assume that this nonrandom planting design did not introduce artifacts into the data.

At the Arkansas site, 120 wild-crop hybrids and 60 wild seedlings were transplanted on 17 June 1996. The timing of planting corresponded to the time when freeliving populations were at a similar life stage (LJS, personal observation). In Ohio, 100 wild-crop hybrids and 50 wild plants were transplanted on 25 June 1996. In both locations, the fields were disked and sprayed with a pre-emergence herbicide for grasses (sethoxydim) before planting. This treatment is similar to what occurs in local agricultural fields. In Ohio, cucumber beetle infestation became intense by late July. These beetles sometimes carry a bacterial disease (bacterial wilt), which causes rapid wilting and death. In order to prevent an excessive loss of experimental plants, all plants were sprayed once using a carbaryl insecticide (Sevin) in a backpack sprayer. Ohio plants were watered and weeded as needed throughout the season. In contrast, the Arkansas plants received only minimal care after planting.

Arkansas plants were observed three times during the season (late June, immediately after planting; mid-August; and mid-September, immediately before harvest). We recorded whether the plants were living, dead, or missing, and counted fruits so that we could account for all fruits at the end of the season. Ohio plants were observed throughout the field season (June-September). On a daily basis, we recorded any mortality and the number of male and female flowers per plant per day (flowers open for just one day before senescing). We also recorded the frequency of virus symptoms twice during the season, once at peak flowering (23 August) and once near the end of the flowering period (18 September). Leaves were classified as having virus symptoms if they had small, deformed leaf blades and mottled coloration. We recorded symptoms for plants on which $>50 \%$ of the leaves had symptoms (symptoms were not recorded in Arkansas). Although we did not carry out enzymelinked immunosorbent assay (ELISA) tests to confirm viral infections, Fuchs \& Gonsalves (1997) reported that visual symptoms were excellent indicators of viral infection in wild and hybrid C. pepo.

At the end of the season, we counted the number of fruits per plant at each site. In addition, we haphazardly sampled one fruit from each of 35 plants per cross type in Ohio and each of 20 plants per cross type in Arkansas, and calculated the average number of seeds per fruit in these categories. To estimate the number of seeds produced per plant, we multiplied the total number of fruits per plant by the average number of seeds per fruit in each category.

\section{7 and 1998 field experiments}

To examine year-to-year and site-to-site variation in the relative performance of hybrid plants, we carried out similar experiments in Arkansas during two subsequent growing seasons. Field 1 was used in both years, along with Field 2 (a previous pasture) in 1997, and Field 3 (previously a soybean field) in 1998. Germinated seedlings were transplanted to the field sites in late June or early July, and the sites were disked as in 1996. Field 1 had low fertility in 1996, so we added $500 \mathrm{~g}$ of fertilizer (15N:15P:10K) in 1997 and 1998. Equal numbers of wild and hybrid plants were randomly assigned to positions that were $5 \mathrm{~m}$ apart at each site (see Table 2 for sample sizes). The fields were divided into blocks in a randomized, complete block design. These experiments also included backcrossed plants that were part of a study which will be described in a forthcoming paper.

In both 1997 and 1998, seedlings were monitored for transplant shock and any that died during the first week were replaced with an extra seedling of the same cross type (as in 1996, few seedlings died and there were no subsequent differences in mortality between wild and hybrid seedlings). Early in the season the fields were disked between plants, and several times per summer we hand-weeded the area around each plant. In 1997, we attempted to create low and high competition levels by weeding only half of Field 1 in a split-plot design. However, local weed densities (mainly Sorghum halepense, Cynodon dactylon, and Cyperus esculentum) were so variable that this treatment had no effect on final seed production or the statistical significance of cross types (ANOvA, not shown). Therefore, this factor 
was dropped and the results were analysed as a randomized, complete block design.

In 1997, both fields were observed several times per week during August and September to note survivorship, flowering, and the occurrence of viral symptoms. In 1998, these observations were made during July and September (Field 3 was not observed for virus symptoms in 1998). We recorded the total number of fruits per plant and counted the number of seeds per fruit in random samples of one fruit from each of 20-40 plants in each cross type. As above, we multiplied fruit number by the average number of seeds per fruit in each cross type to calculate the number of seeds per plant.

\section{Statistical analyses}

Survivorship, virus symptoms, and other categorical data were analysed using $G$-tests. All other data were analysed using SAS statistical software (SAS, 1990). Ohio data on flower and seed number were logtransformed to correct for heteroscedasticity and analysed using a $t$-test. For 1996 Arkansas data, heteroscedasticity was more extreme so we used a Wilcoxon rank-sum test to analyse differences in fruit and seed number between cross types. The 1997 and 1998 data were analysed as randomized complete block ANOVAs to test for effects of cross type and block on fruit and seed number per plant. These data were logtransformed to account for heteroscedasticity.

\section{Results}

\section{Morphology of wild and hybrid plants}

Wild plants displayed a viny habit with tendrils at each node, whereas hybrids were typically somewhat bushy with much shorter internodes and usually no tendrils (more similar to crop plants). However, several hybrids had wild characteristics such as increased internode length, viny habit, and tendrils. Fruit colour, size, and shape also varied between cross types, with hybrids showing a wide range of variation, including both parental fruit types, whereas wild fruits were consistently small, round, and dark green or off-white.

\section{Survival, flowering and lifetime fecundity}

In all experiments, the plants had high survivorship and there were no significant differences between cross types ( $G$-tests; see original and final sample sizes in Table 2). The flowering times of wild and hybrid plants overlapped extensively (Fig. 1 and LJS, personal observation). In Ohio, hybrids began producing male and female flowers concurrently on 20 July 1996, whereas

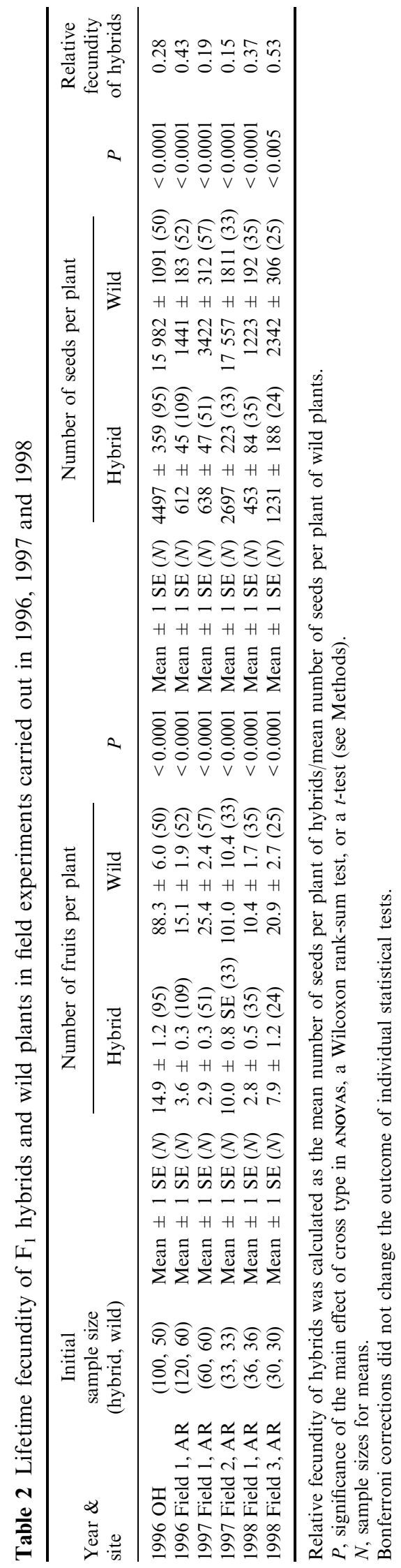

(C) The Genetics Society of Great Britain, Heredity, 86, 694-702. 

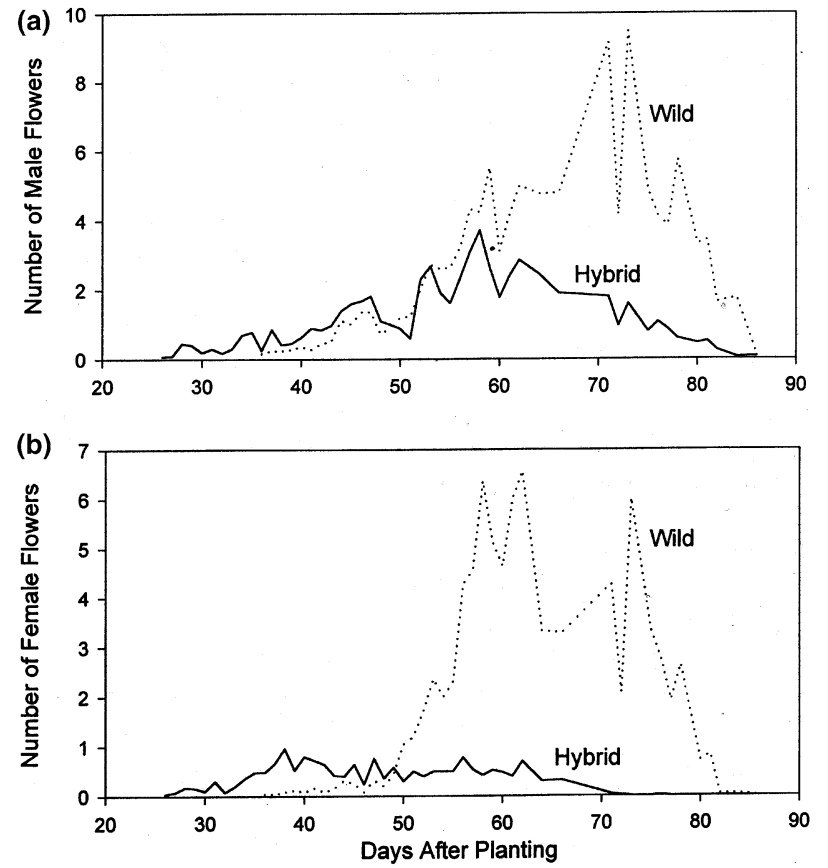

Fig. 1 Male (a) and female (b) flowering phenology, shown as mean number of flowers per plant per day in Ohio in 1996. Numbers of plants per cross type are shown in Table 2. Day 20 is July 15 .

wild plants began producing male flowers on 31 July and female flowers two days later (Fig. 1). The number of male and female flowers per plant also differed between cross types, with wild plants having the most flowers of each type (Fig. 1). Hybrids produced $41 \%$ as many male flowers as wild plants and $21 \%$ as many female flowers. We were not able to quantify total male and female flower production in the Arkansas experiments, but similar differences between cross types were observed.

At all sites and years, hybrids produced significantly fewer seeds per plant than wild plants (Table 2). Hybrids had far fewer fruits per plant (Table 2), although their fruits were typically larger and contained about $30-45 \%$ more seeds than wild plants (LJS, unpublished data). From an evolutionary standpoint, it is useful to calculate the relative fecundity of hybrids as compared to wild plants in the same experiments (average seed number of hybrids/average seed number of wilds). This value ranged from 0.15 to 0.53 in the six experiments, with a mean of 0.33 across experiments $(N=6$, Table 2). The average number of seeds per hybrid ranged from a low of 453 (Field 1, 1998) to a high of 4497 (Ohio, 1996), whereas the range for wild plants was 1223 (Field 1, 1998) to 17557 (Field 2, 1997). Clearly, there was a great deal of variation among sites and years in total seed production and the relative fecundity of hybrid plants.

\section{Putative viral symptoms}

Although we did not confirm viral infection by means of ELISA tests, it is noteworthy that hybrids exhibited significantly lower frequencies of viral symptoms than wild plants (Fig. 2). At least half of the hybrids inherited transgenic resistance to both WMV2 and ZYMV, and it seems likely that one or both of these viruses infected the non-resistant experimental plants. At the Ohio site, two nearby pumpkin fields had high natural frequencies of WMV2 infection ( $100 \%$ by late August) but no apparent infection by ZYMV or other cucurbit viruses (based on ELISA analyses by Dr C. Welty, Ohio State University, personal communication to LJS). Also, an adjacent planting of zucchini squash had a high infection rate from an unknown virus in mid-August (LJS, personal observation).

Virus symptoms became apparent in the Ohio experiment about $45 \mathrm{~d}$ after planting ( $\sim 10$ August, prior to peak flowering), and became quite severe on a number of wild plants by the end of August. Fields in Arkansas were observed in 1997 and 1998, and the frequency of viral symptoms varied among years and sites (Fig. 2). Symptoms were most common in Field 2 in 1997, where nearly all of the wild plants exhibited symptoms. Unlike the situation in Ohio, other cucurbit populations that

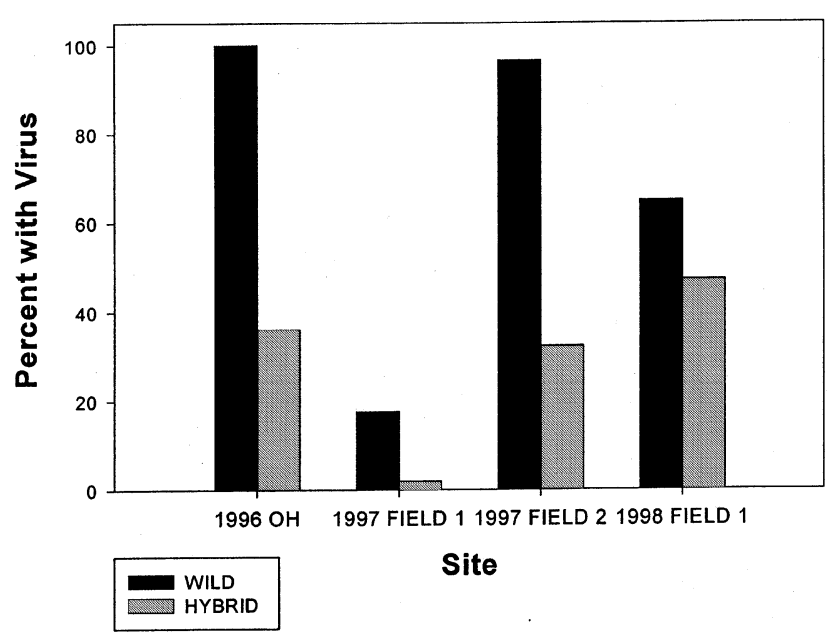

Fig. 2 Frequencies of wild and $F_{1}$ hybrid plants at each field site with virus symptoms (leaves with small, deformed leaf blades and mottled coloration) in September 1996-98. In 1996 only, we report proportions for plants with symptoms on more than half of their leaves; presence/absence data were recorded in 1997-98. For sample sizes, see Table 2. Differences between cross types were significant based on $G$-tests $(1996, G=62.0$, $P<0.0001 ; 1997$ Field 1, $G=8.3, P<0.005 ; 1997$ Field 2, $G=31.2, P<0.0001 ; 1998 G=9.6, P<0.005)$. Bonferroni corrections did not change the outcome of individual statistical tests. 
might also serve as viral hosts were not observed near our experimental populations (i.e. none were seen within $\sim 5 \mathrm{~km}$ ). At all sites, it is possible that the symptoms we observed were due to viruses other than WMV2 and ZYMV.

Although leaf area was greatly reduced in many of the plants with viral symptoms, these plants continued to produce large numbers of fruits. Potyviruses cannot be passed to seeds (Provvidenti et al., 1978), but the physiological effects on the parents may still cause lower quality seeds to be produced. The seeds of infected plants in our experiments appeared to have developed normally.

\section{Discussion}

This study demonstrates that hybrids between transgenic yellow squash and wild $C$. pepo are vigorous enough to contribute to the gene pool of subsequent generations, thereby allowing neutral and beneficial crop genes to introgress into free-living populations. Survival, male flower production, flowering phenology, and seed production are important components of plant fitness that can affect this process. In six field experiments, we found that survival of young plants was uniformly high for both wild and hybrid plants. In Ohio, hybrids produced $43 \%$ as many male flowers but only $28 \%$ as many seeds per plant as wild plants, suggesting that hybrids may perform better as pollen donors than as maternal parents. In Arkansas, the average fecundity of hybrid plants ranged from a low of $15 \%$ relative to wild plants to a high of $53 \%$ (Table 2). Flowering times of wild and hybrid plants overlapped extensively, allowing hybrids to backcross with neighbouring wild plants. Seed survivorship and germination could also affect the fitness of wild-crop hybrids, but we were not able to examine these life stages in the present study.

Year-to-year and site-to-site variation in the relative fecundity of hybrids was striking ( $>$ threefold), and did not seem to be correlated with the total fecundity of either wild or hybrid plants (Table 2). Based on the seed production of our experimental plants, Field 1 appeared to be less fertile than the other sites. Also, both cross types had higher fecundity in 1997 than in 1998, which was relatively dry. Perhaps differences in weather, soil conditions, herbivore densities, competition with local weeds, disease, or other factors led to the genotype-byenvironment interactions that we observed. Viral symptoms were more common at some sites than others. Fewer hybrids had symptoms than wild plants, but we do not know whether viral infections actually occurred in these plants or had any effect on lifetime seed production.
It is important to note that the wild plants used in this study originated from nonagricultural areas along the Buffalo and White River watersheds in Arkansas. Although there is no evidence for genetic differentiation between wild and weedy populations of $C$. pepo (e.g. Decker, 1988; Cahoon, 1995), further studies may reveal that such differences exist. If this is the case, the relative fecundity of crop-weed hybrids may differ from the range of values reported here for crop-wild hybrids. Weedy populations from agricultural areas might be better adapted to agricultural conditions than wild plants and may even have a history of introgression with the crop. If so, differences between weedy populations and crop-weed hybrids could be smaller than the differences we observed. It is also possible that our results would be different if wild-crop hybrids were studied in native habitats, such as disturbed areas along floodplains and river banks, rather than in tilled fields. Given the vigour and variability of $F_{1}$ wild-crop hybrids, however, we assume that these genotypes would be able to survive and reproduce successfully in nonagricultural habitats also.

Our results suggest that the $F_{1}$ generation does not constitute a strong barrier to introgression, despite the fact that some crop genes may be disadvantageous to wild squash. Crop traits that may be deleterious include less branching, shorter internodes, fewer flowers per plant (especially fewer female flowers), and lower concentrations of cucurbitacins. Hybrids may be more susceptible to insect herbivores than wild plants, since hybrids in the Ohio experiment were six times more likely to exhibit leaf damage from spotted and striped cucumber beetles (Diabrotica undecimpunctata and Acalymma vitatum) than wild plants (LJS, unpublished data). Despite the fact that hybrids possess certain deleterious crop traits, recombination should allow nondeleterious genes that are not tightly linked to these loci to persist in backcrossed generations. In subsequent studies, we found that the survival and fecundity of wild-crop $F_{1}$ hybrids with Freedom III transgenic virusresistance was similar to that of $F_{1}$ plants that lacked this transgene construct, which exhibited Mendelian segregation ratios (Spencer and Snow, in prep.). Therefore, we conclude that neutral or beneficial transgenes will spread from the crop to wild populations of $C$. pepo within a few generations after they come into contact.

Our results are consistent with preliminary reports from Drs M. Fuchs and D. Gonsalves at Cornell University (Fuchs \& Gonsalves, 1997, 1999). They crossed an accession of wild C. pepo with the transgenic parent ('CZW-3') of Freedom III squash, which has a single copy of a transgene construct conferring resistance to CMV, ZYMV, and WMV2. Field experiments conducted in New York showed that the transgene 
construct was successfully transmitted from wild-crop hybrids to neighbouring wild plants. In addition, transgenic $F_{1}$ hybrids produced more seeds than nontransgenic hybrids when exposed to artificially induced viral disease pressure. Next, it is important to document the frequency and severity of viral infections within the plant's natural range in the south-central USA, and to ask whether transgenic resistance to cucurbit viruses could affect the population dynamics of wild and weedy populations. These types of empirical studies will aid in determining whether novel, fitness-related traits from the crop could enhance the abundance and invasiveness of a native weed.

\section{Acknowledgements}

We thank A. Wszcelaki, T. Culley, C. Franklin, P. Morán Palma, T. Kirkpatrick, and the staff of the University of Arkansas Southwest Research and Extension Center for logistical support; H. Wilson, D. Decker-Walters, H. Quemada, B. Schaal, A. Stephenson, and T. Andres for advice on the biology of wild squash; S. Nameth for help identifying virus symptoms; B. Smith for providing wild seeds; and S. Selbo and two anonymous reviewers for comments on the manuscript. This work was supported by grants from the Janice Carson Beatley Fund of the Department of Evolution, Ecology, and Organismal Biology, Ohio State University.

\section{References}

ARNOLD, M. L. 1997. Natural Hybridization and Evolution. Oxford University Press, New York.

ARRIOlA, P. E. AND Ellstrand, N. C. 1996. Crop-to-weed gene flow in the genus Sorghum (Poaceae): spontaneous interspecific hybridization between Johnsongrass, Sorghum halepense, and crop sorghum, S. bicolor. Am. J. Bot., 83, 1153-1160.

ARRIOLA, P. E. AND EllStRAND, N. C. 1997. Fitness of interspecific hybrids in the genus Sorghum: persistence of crop genes in wild populations. Ecol. Appl., 7, 512-518.

CAHOON, K. S. 1995. Systematics and Origins of Cucurbita pepo Gourds from the Lower Mississippi River Valley. PhD Dissertation, Washington University, St. Louis, MO.

COWAN, C. W. AND SMITH, B. D. 1993. New perspectives on a wild gourd in Eastern North America. J. Ethnobiol., 13, 17-54.

DECKER, D. S. 1988. Origin(s), evolution, and systematics of Cucurbita pepo (Cucurbitaceae). Econ. Bot., 42, 4-15.

Ellstrand, N. C., PRENTICE, H. C. AND HANCOCK, J. F. 1999. Gene flow and introgression from domesticated plants into their wild relatives. Ann. Rev. Ecol. Syst., 30, 539-563.

FUCHS, M. AND GONSALVES, D. 1997. Risk assessment of gene flow associated with the release of virus resistant transgenic crop plants. In: Tepfer, M. and Balasz, E. (eds) VirusResistant Transgenic Crop Plants: Potential Ecological
Impact, pp. 114-120. INRA Editions/Springer Verlag, Berlin.

FUCHS, M. AND GONSALVES, D. 1999. Risk assessment of gene flow from a virus-resistant transgenic squash into a wild relative. In: Ammann, K., Jacot, Y., Simonsen, V. and Kjellsson, G. (eds) Methods for Risk Assessment of Transgenic Plants. III. Ecological Risks and Prospects of Transgenic Plants, pp. 141-143. Birkhäuser Verlag, Basel.

JiANG, C., CHEE, P. W., DRAYE, X., MORRELl, P. L. ET AL. 2000. Multilocus interactions restrict gene introgression in interspecific populations of polyploid Gossypium (cotton). Evolution, 54, 798-814.

JøRGENSEN, R. B. AND ANDERSEN, B. 1994. Spontaneous hybridization between oilseed rape (Brassica napus) and weedy $B$. campestris (Brassicaceae): a risk of genetically modified oilseed rape. Am. J. Bot., 81, 1520-1526.

KIRKPATRICK, K. J. AND WILSON, H. D. 1988. Interspecific gene flow in Cucurbita: C. texana vs. C. pepo. Am. J. Bot., 75, 519-527.

KLINGER, T. AND ELLSTRAND, N. C. 1994. Engineered genes in wild populations: fitness of weed-crop hybrids of Raphanus sativus. Ecol. Appl., 4, 117-120.

LANGEVIN, S. A., CLAY, K. AND GRACE, J. B. 1990. The incidence and effects of hybridization between rice and its related weed red rice (Oryza sativa L.). Evolution, 44, 1000-1008.

LINDER, C., TAHA, I., SEILER, G., SNOW, A. ET AL. 1998. Longterm introgression of crop genes into wild sunflower populations. Theor. Appl. Genet., 96, 339-347.

PROVVIDENTI, R., ROBINSON, R. W. AND MUNGER, H. M. 1978. Resistance in feral species to six viruses infecting Cucurbita. Plant Dis. Reporter, 62, 326-329.

RENNO, J.-F., WINKEL, T., BONNEFOUS, F. AND BEZANCON, G. 1997. Experimental study of gene flow between wild and cultivated Pennisetum glaucum. Can. J. Bot., 75, 925-931.

RIESEBERG, L. H. AND LINDER, C. R. 1999. Hybrid classification: insights from genetic map-based studies of experimental hybrids. Ecology, 80, 361-370.

SAS. 1990. SAS/STAT user's guide, 4th edn., vol. 1. SAS Institute, Cary, NC.

SCHUltheIS, J. R. AND WAlters, S. A. 1998. Yield and virus resistance of summer squash cultivars and breeding lines in North Carolina. HortScience, 8, 31-39.

SMALL, E. 1984. Hybridization in the domesticated-weed-wild complex. In: Grant, W. F. (ed.) Plant Biosystematics, pp. 195-210. Academic Press, Toronto.

SNOW, A. A. AND MORÁN PALMA, P. 1997. Commercialization of transgenic plants: potential ecological risks. BioScience, 47, 86-96.

SNOW, A. A., MORÁN PALMA, P., RIESEBERG, L. H., WSZCELAKI, A. ET AL. 1998. Fecundity, phenology, and seed dormancy of $\mathrm{F}_{1}$ hybrids in sunflower (Helianthus annuus, Asteraceae). Am. J. Bot., 85, 794-801.

TALLAMY, D. W. AND KRISCHIK, v. A. 1989. Variation and function of cucurbitacins in Cucurbita: an examination of current hypotheses. Am. Nat., 133, 766-786.

TRICOl, D. M., CARNeY, K. J., RUSSEll, P. F., MCMASTER, J. R. ET AL. 1995. Field evaluation of transgenic squash containing single or multiple virus coat protein gene constructs for 
resistance to cucumber mosaic virus, watermelon mosaic virus 2, and zucchini yellow mosaic virus. Bio/Technology, 13, 1458-1465.

USDA/APHIS (UNITED STATES DEPARTMENT OF AGRICULTURE/ANIMAL AND PLANT HEALTH INSPECTION SERVICE). 1994. Environmental Assessment for Upjohn Company/Asgrow Seed Company petition for determination of non-regulated status for ZW-20 squash. USDA/APHIS, Hyattsville, MD.

VAN GAAL, T. M., GALATOWITSCH, S. M. AND STREFELER, M. S. 1998. Ecological consequences of hybridization between a wild species (Echinacea purpurea) and related cultivar (E. purpurea "White Swan"). Sci. Hort., 76, 73-88.

walkey, D. 1991. Applied Plant Virology, 2nd edn. Chapman \& Hall, London.
WeidemanN, G. J. AND TEMPleton, G. E. 1988. Control of Texas gourd, Cucurbita texana, with Fusarium solani f. sp. cucurbitae. Weed Technol., 2, 271-274.

WILSON, H. D. 1990. Gene flow in squash species. Domesticated Cucurbita species may not represent closed genetic systems. BioScience, 40, 449-455.

WILSON, H. D. 1993. Free-living Cucurbita pepo in the United States: viral resistance, gene flow, and risk assessment. Report for USDA Animal and Plant Health Inspection Service, Hyattsville, MD.

ZEMETRA, R. S., HANSEN, J. AND MALLORY-SMITH, C. A. 1998. Potential for gene transfer between wheat (Triticum aestivum) and jointed goatgrass (Aegilops cylindrica). Weed Sci., 46, 313-317. 